\title{
DERIVATION OF TRANSTHORACIC ECHOCARDIOGRAPHIC REFERENCE RANGES FOR LEFT VENTRICULAR M-MODE DIMENSIONS IN PRETERM INFANTS
}

\author{
R. Warrier ${ }^{1}$, E.S. Tan ${ }^{2}$, A. Sehgal ${ }^{3}$, S.A. Hope ${ }^{2}$ \\ ${ }^{1}$ Paediatrics, The Canberra Hospial, Canberra, ACT, ${ }^{2}$ Monash Heart, Monash Medical Centre, Clayton, \\ ${ }^{3}$ Newborn Services, Monash Medical Centre, Clatyon, VIC, Australia
}

Background: M-mode measurement of left ventricular systolic and diastolic dimensions is routine in transthoracic echocardiography. Reference ranges are well defined in adults and paediatric patients. No such data have been published in preterm neonates.

Methods: All echocardiographic studies performed in Monash Newborn between $15^{\text {th }}$ November 2006 and $2^{\text {nd }}$ December 2010 were identified. Infants with congenital heart disease or a moderate or larger patent ductus arteriosus were excluded. Analysis was limited to infants with a birth or current weight $\leq 3.5 \mathrm{~kg}$ and $\leq$ 45 completed weeks of corrected gestational age (cGA) at the time of echocardiography. Analysis was perfomed in SPSS. Regression curves were modelled with respect to weight and cGA and reference curves for \pm 1 and \pm 2 standard deviations calculated using the method of Altman (Statistics in Medicine 1993).

Results: 438 studies were identified, mean GA at birth 30 weeks, birth weight $1.5 \pm 0.9 \mathrm{~kg}$. Left ventricular systolic and diastolic dimensions increased with weight and cGA (all $P<0.001$ ). Standard deviation was constant over the given weight range, but increased with increasing cGA.

Conclusions: The derivation of reference ranges for left ventricular dimensions in preterm infants will permit better recognition of abnormalities and better description and documentation of change with the opportunity to calculate $\mathrm{Z}$ scores. 